\title{
TOWARD AN INTEGRATED OBSERVING SYSTEM FOR OCEAN CARBON AND BIOGEOCHEMISTRY AT A TIME OF CHANGE
}

\author{
Nicolas Gruber ${ }^{(1)}$, Arne Körtzinger ${ }^{(2)}$, Alberto Borges ${ }^{(3)}$, Hervé Claustre $^{(4)}$, Scott C. Doney ${ }^{(5)}$, Richard A. Feely ${ }^{(6)}$, \\ Maria Hood $^{(7)}$, Masao Ishii ${ }^{(8)}$, Alexander Kozyr ${ }^{(9)}$, Pedro Monteiro ${ }^{(10)}$, Yukihiro Nojiri ${ }^{(11)}$, Christopher L. Sabine $^{(6)}$, \\ Ute Schuster $^{(12)}$, Douglas W.R. Wallace ${ }^{(2)}$ and Rik Wanninkhof ${ }^{(13)}$ \\ ${ }^{(1)}$ Institute of Biogeochemistry and Pollutant Dynamics, ETH Zurich, Zürich, Switzerland. \\ E-mail: nicolas.gruber@env.ethz.ch

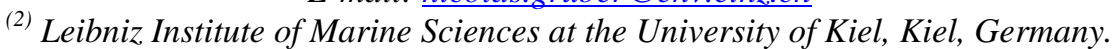 \\ E-mail: akoertzinger@ifm-geomar.de, dwallace@ifm-geomar.de \\ ${ }^{(3)}$ Institut de Physique, Université de Liège, B-4000 Liège, Belgium. \\ E-mail: alberto.borges@ulg.ac.be \\ (4) CNRS and Université P. \& M. Curie, Laboratoire d'Océanographie de Villefranche, 06230 Villefranche-sur-Mer, \\ France. E-mail: claustre@obs-vlfr.fr \\ ${ }^{(5)}$ Woods Hole Oceanographic Institution, Woods Hole, MA, USA. E-mail: sdoney@ whoi.edu \\ ${ }^{(6)}$ NOAA Pacific Marine Environmental Laboratory, Seattle, WA, USA. \\ E-mail: Richard.A.Feely@noaa.gov, Chris.Sabine@noaa.gov \\ (7) Intergovernmental Oceanographic Commission of UNESCO, 1 rue Miollis, 75732 Paris, France. \\ Email: maria.hood@ioccp.org \\ ${ }^{(8)}$ Meteorological Research Institute, JMA, Nagamine 1-1, Tsukuba, Ibaraki, 305-0052, Japan. \\ E-mail:mishii@mri-jma.go.jp \\ (9) Carbon Dioxide Information Analysis Center (CDIAC), Oak Ridge National Laboratory, Oak Ridge, TN 37831-6335, \\ USA.E-mail: kozyra@ornl.gov \\ ${ }^{(10)}$ Ocean Systems \& Climate Group, CSIR, Stellenbosch 7599, South Africa.E-mail: pmonteir@csir.co.za \\ ${ }^{(11)}$ National Institute for Environmental Studies, 16-2, Onogawa, Tsukuba, Ibaraki, 305-0053, Japan. \\ E-mail: nojiri@nies.go.jp \\ ${ }^{(12)}$ School of Environment Sciences, University of East Anglia, Norwich, NR4 7TJ, UK. E-mail: u.schuster@uea.ac.uk \\ ${ }^{(13)}$ NOAA/AOML 4301 Rickenbacker Causeway Miami, FL 33149, USA. E-mail: rik.wanninkhof@noaa.gov
}

\section{ABSTRACT}

Ocean biogeochemical cycles are currently undergoing fundamental changes - largely as a consequence of the addition of greenhouse gases to the atmosphere. The oceans are getting warmer, and their $\mathrm{pH}$ and oxygen levels are decreasing. Further changes may arise as a consequence of the perturbation of the global nitrogen cycle, leading to higher inputs of fixed nitrogen to the ocean by rivers and enhanced deposition of nitrogen to the surface ocean. These biogeochemical changes plus the concomitant changes in ocean circulation will have profound effects on some of the ocean's key services, i.e. its capability to mitigate climate change by removing anthropogenic $\mathrm{CO}_{2}$ from the atmosphere, and its provision of important ecosystem services such as food and biodiversity. Documenting, understanding, and predicting these biogeochemical changes require a concerted and sustained observational effort that includes both the continuation of well-tested approaches and the development and implementation of novel systems. Of particular importance for the first set of approaches are the sustaining and extension of (i) a surface ocean volunteer ocean ship-based observing system primarily focusing on the determination of the air-sea exchange of $\mathrm{CO}_{2}$ and upper ocean changes in
\end{abstract}

carbonate chemistry, of (ii) an interior ocean researchship based system focusing on large-scale interior changes of the ocean's biogeochemistry (carbon, oxygen, nutrients, etc), and of (iii) ship-based and moored time-series observations at key sites, including the coastal ocean. Of particular importance for the second set of approaches are (i) the accelerated improvement, development and implementation of new observational elements on the Argo (Array for Realtime Geostrophic Oceanography) array (especially oxygen, but also nutrient and bio-optical sensors), and (ii) the development, testing, and deployment of novel sensors for the ocean's carbon system. Concerted synthesis efforts involving also novel approaches for merging observations with biogeochemical models will ensure that these observational elements realize their synergistic potential.

\section{INTRODUCTION}

For the last 250 years, mankind has been emitting ever increasing amounts of greenhouse gases (most importantly $\mathrm{CO}_{2}$ (carbon dioxide)) to the atmosphere, first primarily as a result of the clearing of forest for cropland and pasture, and since the turn of the $20^{\text {th }}$ century primarily as a result of the burning of fossil 
fuels [1]. In response, atmospheric $\mathrm{CO}_{2}$ has increased by more than 100-ppm (30\%), with today's concentration of about 390-ppm representing a level that Earth's atmosphere likely has not experienced for more than 20 million years [70].

This accumulation of extra $\mathrm{CO}_{2}$ and other greenhouse gases in the atmosphere has already warmed the planet by about $0.8^{\circ} \mathrm{C}$ since pre-industrial times ([70], and with atmospheric $\mathrm{CO}_{2}$ being bound to increase further, an extra warming of at least $1.2^{\circ} \mathrm{C}$ will occur with high likelihood. This warming since the preindustrial period of at least $2{ }^{\circ} \mathrm{C}$ will have profound effects throughout Earth's climate system. It will penetrate into the ocean, causing changes in the physical environment that will trigger a cascade of responses in the ocean's biogeochemical systems [2] and [3].

By taking up nearly $30 \%$ of the total anthropogenic emissions of $\mathrm{CO}_{2}$, the ocean has so far helped substantially to mitigate climate change. Without this uptake, atmospheric levels today would already have far exceeded the 450-ppm level that corresponds roughly to the maximum $\mathrm{CO}_{2}$ level allowable to keep global warming below the $2^{\circ} \mathrm{C}$. threshold.

This service comes with a huge penalty whose ramifications are only beginning to emerge: Ocean acidification. The absorption of $\mathrm{CO}_{2}$ from the atmosphere not only reduces the $\mathrm{pH}$ of the ocean, it also lowers the concentration of the carbonate ion and hence the saturation state of seawater with regard to mineral forms of $\mathrm{CaCO}_{3}$ (calcium carbonate) [4]. These chemical changes will affect ocean organisms, both positively and negatively (see e.g. [3], [2] and [5]). While most studies to date have shown a decrease in calcification for pelagic calcifying groups such as coccolithophores, foraminifera, and pteropods in response to seawater acidification (e.g., [6]; [7] and 8]) there is also contradicting evidence (e.g., [9]). In addition, non-calcifying organisms are affected, although the magnitude and sign of their response is not clear yet [5].

Global change will affect not only temperature, but also wind patterns, and evaporation and precipitation, likely causing changes in ocean circulation and mixing as well. A relatively robust projection for this century is an increase in upper ocean stratification, in part driven by upper ocean warming (low to temperate latitudes), and upper ocean freshening (high latitudes). An increase in upper ocean stratification leads to a reduced overall uptake of anthropogenic $\mathrm{CO}_{2}$, leading to an accelerated increase in atmospheric $\mathrm{CO}_{2}$ and surface ocean acidification, as well as to a reduced transport of oxygen from the near-surface ocean to the interior. This will amplify the loss of oxygen from the ocean induced from the warming, causing a substantial decrease in the ocean's mean concentration of dissolved oxygen [10].
This deoxygenation will lead to a reduction of the overall volume of the ocean that is habitable for fish and other marine organisms that critically depend on substantive levels of oxygen. Likely, it will also lead to an expansion of the oxygen minimum zones (OMZ), thereby enhancing the production and subsequent emission of $\mathrm{N}_{2} \mathrm{O}$ (nitrous oxide) and $\mathrm{CH}_{4}$ (methane), which are much more potent greenhouse gases than $\mathrm{CO}_{2}$ itself [11].

Humankind has also substantially perturbed the global nitrogen cycle [12]; primarily as a result of the invention of the Haber-Bosch process that has permitted humans to fix molecular nitrogen from air into biologically available forms of "fixed" nitrogen at an industrial scale [13]. While this process has permitted humans to greatly expand global food production, it has led to increases in the fixed nitrogen load that rivers transport to the ocean, causing coastal eutrophication and associated local hypoxia and anoxia (e.g. [14]). In addition, increasing levels of fixed nitrogen are deposited onto the ocean's surface, potentially stimulating ocean productivity, but also enhancing acidification. Globally, the impact of this deposition appears to have remained relatively marginal, but in a few regions, this atmospherically derived nitrogen is very substantial relative to natural sources [15]

Finally, point sources from industrial discharges and oil spills, as well as diffuse sources such as atmospheric deposition bring a large number of metals (e.g. methyl mercury) and persistent organic pollutants into the ocean (e.g. [16]). While most of the focus is put on understanding the immediate effect of these pollutants when their concentrations are still high close to their sources, less is known at the much lower, but in many situations still easily detectable concentrations in the open ocean far away from the source. Many persistent organic pollutants and also methyl mercury tend to bioaccumulate, i.e. the concentrations of these substances in the tissues of organisms tend to increase with increasing trophic level. It is therefore conceivable that some of these substances impact marine ecosystems even at relatively low ambient concentration, affecting also the ocean's biogeochemical cycles.

These long-term biogeochemical changes occur against a background of substantial variability on time scales from days to decades, and on spatial scales from kilometres to entire ocean basins. On one hand, these natural variations often obscure the identification of long-term trends, but on the other hand, they provide an important opportunity for the development of an understanding of the processes underlying ocean biogeochemistry and ecosystems.

The ability to observe ocean biogeochemistry has made substantial advances in the last decade since OceanObs'99. Fundamental achievements are the 
establishment and extension of a global network of voluntary observing ships (VOS), the initiation of the CLIVAR/ $\mathrm{CO}_{2}$ (Climate Variability and Predictability) [17], the development of a mooring network and the implementation of a global float-based observatory. But, the changes in ocean biogeochemistry looming ahead, and our need to document, understand, and ultimately predict these changes, require us to make the next big step forward. This involves the continuation and strengthening of a series of well-established and timeproven approaches. but it also requires an investment in the continuing development, testing and ultimately large-scale deployment of new observing system technologies.

In the next sections, we first highlight some of the key successes of ocean biogeochemical cycle research in the past decade, then go on to describe major recent development of ocean observation capabilities and networks and finally lay out the way ahead including major implementation steps and elements.

\section{OBSERVING OCEAN BIOGEOCHEMISTRY: THE KEY SUCCESSES OF THE PAST DECADE}

For decades, the main driving questions for ocean carbon cycle research have been: How much anthropogenic carbon is the ocean taking up from the atmosphere, where does this occur, and where is this carbon ultimately stored in the ocean (e.g. [18]). Until very recently, the answers to these questions were either provided by models or by indirect methods involving other tracers. In addition, little was known about seasonal to decadal variability in ocean biogeochemistry, since sampling typically has been spotty in time and space. The past decade has seen a dramatic increase in our knowledge and understanding with respect to these questions: A surface ocean-based observation network has provided for the first time with the means to obtain a climatological picture of the sources and sinks of $\mathrm{CO}_{2}$ on a global basis; Ocean interior measurements have revealed how much $\mathrm{CO}_{2}$ the ocean has taken up since pre-industrial times and where this carbon is stored; Long-term time-series observations have demonstrated the importance of seasonal to decadal variability. The first two observing elements have provided us with two iconic maps of the ocean carbon cycle.

\subsection{Ocean $\mathrm{CO}_{2}$ flux climatology}

Measurements of the surface ocean partial pressure of $\mathrm{CO}_{2}\left(p \mathrm{CO}_{2}\right)$ coupled with simultaneous measurements of atmospheric $p \mathrm{CO}_{2}$ provide the most powerful window into the study of fluxes of $\mathrm{CO}_{2}$ across the airsea interface, i.e. whether the ocean at a given location and time represents a source or sink for atmospheric $\mathrm{CO}_{2}$. The oceanic $p \mathrm{CO}_{2}$ measurements also give insights into the underlying processes, such as how much of the $\mathrm{CO}_{2}$ exchange is driven by warming or cooling, and what is the role of surface ocean biology.

High-quality measurements of properties of the $\mathrm{CO}_{2}$ system in surface waters started more than half a century ago during the International Geophysical Years (e.g., [19] and [20]). For decades after, such measurements were exclusively performed from research vessels. It was only in the late 1990s when semi-autonomous surface ocean (and atmosphere) $p \mathrm{CO}_{2}$ measurements started to be carried out from merchant vessels as well, that a global coverage became possible. Since both these two ship-platforms are usually sailing through a particular region for reasons other than measuring surface ocean $\mathrm{CO}_{2}$ properties, these platforms are usually referred to as "ships of opportunity" (SOOP) (see also [21]).

This development culminated in the synthesis of the observations in the form of a global $\mathrm{pCO}_{2}$ climatology, the latest edition of which is based on more than 3 million measurements [22]. The estimates of the global climatological distribution of $\mathrm{CO}_{2}$ sources and sinks that emerge from this $\mathrm{pCO}_{2}$ climatology form one of the icons of marine $\mathrm{CO}_{2}$ research (Fig. 1). The tremendous growth of the most recent database since the publication of the first climatology in 1997 [23] has allowed for a significantly improved robustness of the constructed $\mathrm{CO}_{2}$ flux maps in terms of geographical coverage and resolution of the seasonal cycle. Key findings include the consolidation of a climatological mean flux of $\mathrm{CO}_{2}$ into the ocean of about $1.6 \pm 0.9 \mathrm{Pg} \mathrm{C} \mathrm{yr}^{-1}$, which, when corrected for the net outgassing of natural $\mathrm{CO}_{2}$ driven by the input of carbon from rivers, yields a net uptake of anthropogenic $\mathrm{CO}_{2}$ of $2.0 \pm 1.0 \mathrm{Pg} \mathrm{C} \mathrm{yr}^{-1}$ for a nominal year of 2000 .

The SOOP-based observation approach for surface ocean $\mathrm{pCO}_{2}$ owes its great success not only to the spatiotemporal coverage achievable by these platforms but also to international coordination and stewardship. Important activities in this context were the execution of international intercomparison exercises (eg. [24] and Nojiri et al., pers. comm. 2003), and the agreement on methods, best practices, data formats, quality control measures and data management mediated to a major extent by the International Ocean Carbon Coordination Project (IOCCP; www.ioccp.org).

\subsection{Inventory of anthropogenic $\mathrm{CO}_{2}$}

The detection of the anthropogenic $\mathrm{CO}_{2}$ accumulated in the ocean based on measurements of the inorganic carbon system has been a major objective of the shipbased global $\mathrm{CO}_{2}$ survey undertaken as part of the joint WOCE/JGOFS (Word Ocean Circulation Experiment/Joint Global Ocean Flux Study) programs in the late 1980s and early 1990s. This project resulted 


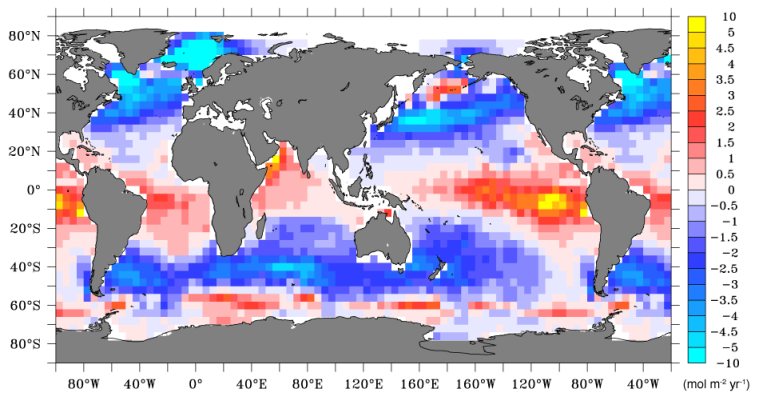

Figure 1: Map of the climatological annual mean airsea flux of $\mathrm{CO}_{2}$ for a nominal year of 2000 (in mol m $\mathrm{m}^{-2}$ $\left.y r^{-1}\right)$. Positive fluxes indicate outgassing. Based on the surface ocean $\mathrm{pCO}_{2}$ data from [22] using a squaredependence of the gas transfer velocity on the wind speed.

in an unprecedented new dataset with global coverage and the necessary high quality to make it possible to isolate the relatively small anthropogenic $\mathrm{CO}_{2}$ signal from the large variability of the natural carbon system in the ocean (see e.g. [25]).

A major accomplishment of the decades since the end of the WOCE/JGOFS program has been the completion of an international effort with the goal to produce a coherent, internally consistent data set through standardized secondary quality control procedures (the GLODAP (Global Ocean Data Analysis Project) effort, [26] and [27]). Together with the development and refinement of anthropogenic $\mathrm{CO}_{2}$ separation methods (e.g. the $\Delta C^{*}$ method of [28]), this data set laid the foundation for the first global estimate of the amount of anthropogenic $\mathrm{CO}_{2}$ that the ocean has taken up since pre-industrial times [29] (Fig. 2).

This map reveals areas of high local accumulation, such as the North Atlantic, and the mid-latitude Southern hemisphere, and areas where little anthropogenic $\mathrm{CO}_{2}$ has accumulated in the last $\sim 250$ years. The global computed inventory of $118 \pm 19 \mathrm{Pg} \mathrm{C}$ up to 1995 represents one of the most fundamental constraints for the global carbon cycle, equally important as the direct evidence of the accumulation of anthropogenic $\mathrm{CO}_{2}$ in the atmosphere. Not only did this number reveal that the ocean has taken up an amount of carbon equivalent to about $45 \%$ of the total fossil fuel emissions since preindustrial times, but also it also permitted [29] to compute the net anthropogenic $\mathrm{CO}_{2}$ exchange of the terrestrial biosphere over this period, turning out to be a net loss of $39 \pm 28 \mathrm{Pg} \mathrm{C}$.

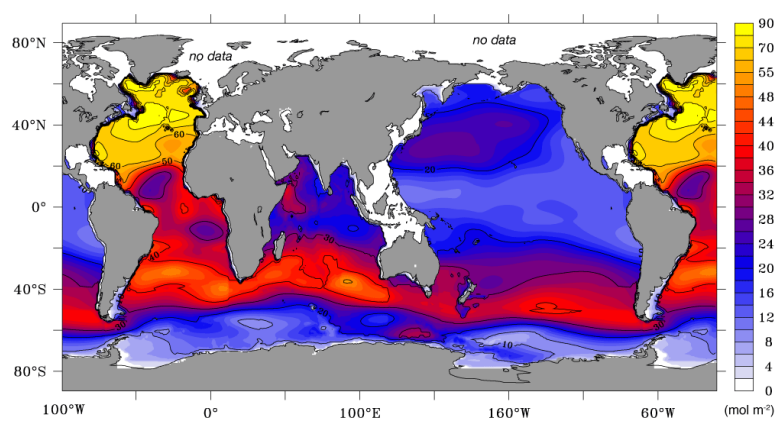

Figure 2: Map of the vertically integrated amount of anthropogenic $\mathrm{CO}_{2}$ stored in the ocean since preindustrial times (in mol m${ }^{-2}$ ). Based on [29].

\subsection{The ocean's Mauna Loa curves}

While the surface ocean $\mathrm{CO}_{2}$ network provides a constraint on the sea-air $\mathrm{CO}_{2}$ fluxes across the surface interface, and the interior ocean network constrains the very long-term increase in the carbon content, it was the establishment of oceanic time-series for inorganic carbon that revealed for the first time how the oceanic carbon cycle truly evolves with time. The longest timeseries for inorganic carbon started in the early 1980s ([30], [31]; [32]) near Bermuda and in 1988 was joined by a second time-series near Hawaii ([33]; [34] and [35]) (Fig. 3). In addition to showing a rich spectrum of variations on seasonal timescales and shorter, these long time-series also reveal unmistakingly the imprint of the oceanic uptake of anthropogenic $\mathrm{CO}_{2}$ from the atmosphere. In fact, the surface ocean $p \mathrm{CO}_{2}$ follows the atmospheric $\mathrm{CO}_{2}$ increase relatively closely at both sites, reflecting the fact that the air-sea equilibration time-scale for the surface ocean $\mathrm{CO}_{2}$ system is about one year, substantially smaller than the characteristic time-scale associated with the increase in atmospheric $\mathrm{CO}_{2}$. The observations also clearly uncover the impact this uptake of $\mathrm{CO}_{2}$ from the atmosphere has on surface ocean $\mathrm{pH}$. Over the course of these 20 years, surface ocean $\mathrm{pH}$ values at both sites have decreased by about $0.017 \mathrm{pH}$ units per decade.

\section{MAJOR RECENT DEVELOPMENTS}

The foundations for the three major accomplishments of the past decade described above were all laid in the 1980 s and early 1990s, highlighting the importance of a long-term perspective when developing an integrated observing system. These accomplishments also demonstrate the high -level of complimentary that the three approaches provide for constraining the large-scale ocean carbon system and its anthropogenic 


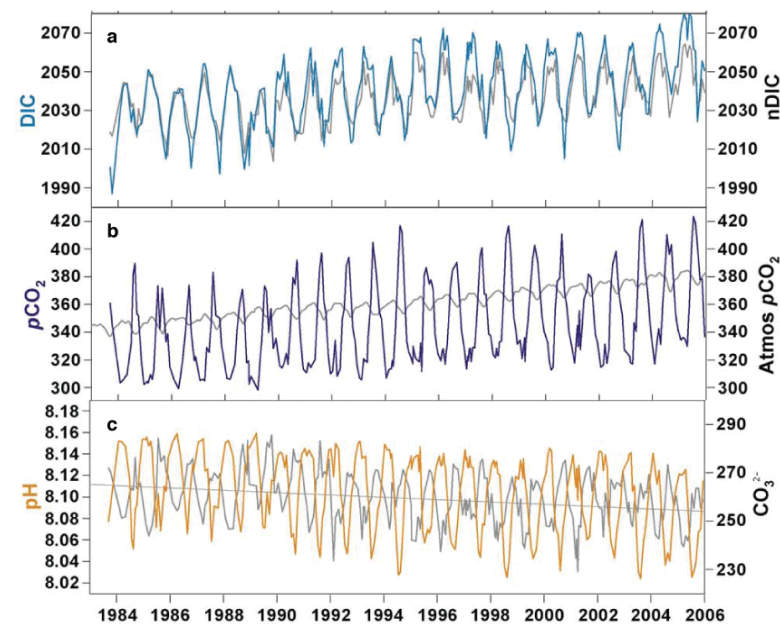

Figure 3: Long-term time-series of surface ocean $\mathrm{CO}_{2}$ properties from two ocean sites near Bermuda, i.e. Station " $S$ " and BATS (Bermuda Atlantic Time-series Station). (a) dissolved inorganic carbon (DIC) (blue) and salinity normalized DIC (grey) (in $\mu \mathrm{mol} \mathrm{kg-1);} \mathrm{(b)}$ surface ocean (purple) and atmospheric pCO2 (grey) in ppm, the latter measured at Bermuda and Terceira; (c)

surface ocean $\mathrm{pH}$ (orange) and carbonate ion concentration (grey). Modified from [32].

change, i.e. the surface ocean network constraining the flux across the top interface [21], the interior ocean network constraining the long-term rate of change of carbon (and also the transport across sub-volumes) [17], and finally the time-series stations providing a temporal perspective and linking the two other approaches ([36].

Nevertheless, these approaches are also subject to major limitations, the most important being the large spatial and temporal gaps inherent in these ship-based programs. For example, even though the most recent $p \mathrm{CO}_{2}$ climatology of [22] is based on more than 3 million observations, there still remain entire sub-basin areas where less than two months had been sampled over the last 30 years (Fig. 4). In addition, the data set is sufficient in only a few regions to reliably determine long-term trends in surface ocean $p \mathrm{CO}_{2}$, and in particular, to reveal whether the ocean carbon system has began to move away in a substantial manner from the behaviour expected for a steady-state ocean.

The focused and intensified implementation of the surface ocean $\mathrm{CO}_{2}$ network in recent years has permitted scientists to make the next step for certain ocean basins and not only identify temporal variations and trends at a few time-series sites, but also for extended regions. Of particular concern are the questions how the surface ocean carbon cycle has responded to past interannual to decadal variations in

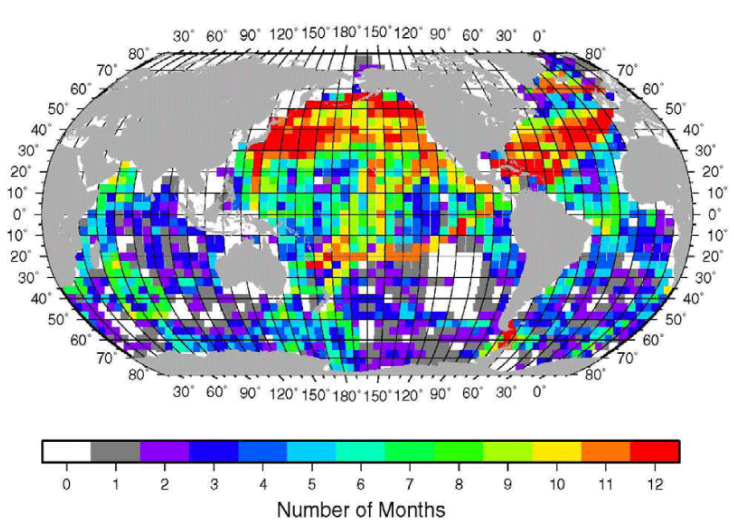

Figure 4: Number of months with $\mathrm{pCO}_{2}$ observation per $5 \times 5^{\circ}$ pixels in the database used by [22]. to construct the climatology used for Fig. 1. From [22].

In recent years, important developments have occurred that permit us - given their continued support and enhanced implementation - to reduce these limitations and be ready for the next wave of challenges, i.e. those associated with the time-varying nature of ocean biogeochemistry.

\subsection{Interannual to decadal variability in basin-scale $\mathrm{CO}_{2}$ fluxes}

climate, and whether the significant anthropogenic changes in climate has already led to long-term secular changes. The first basin-scale assessments were achieved in the tropical Pacific, thanks to the intense and regular surveys undertaken in the context of the TOGA-TAO (Tropical Ocean Global Atmosphere/Tropical Atmosphere Ocean) moorings (e.g. [4]). These data demonstrated the large impact that the change from La Niña to El Niño conditions has on surface ocean $p \mathrm{CO}_{2}$, leading to dramatic reduction in the $\mathrm{CO}_{2}$ source strength of the tropical Pacific to the atmosphere. More recently, the data density in the Atlantic became good enough to establish in detail the variations in the sink strengths in the temperate North Atlantic (Fig. 5, [37]). These appear to be strongly congruent with the dominant mode of climate variability in the North Atlantic, i.e. the North Atlantic Oscillation, highlighting the strong impact of climate variations on the surface ocean carbon cycle.

So far, it has been very difficult to establish with confidence long-term secular trends that span at least two decades (see e.g. [38])). A region of particular emphasis is the Southern Ocean, where model simulations and atmospheric data suggest a recent slowing of the uptake of $\mathrm{CO}_{2}$ from the atmosphere ([39] and [40]). The limited available in-situ observations tend to support these findings, but the confidence is low [41]. 


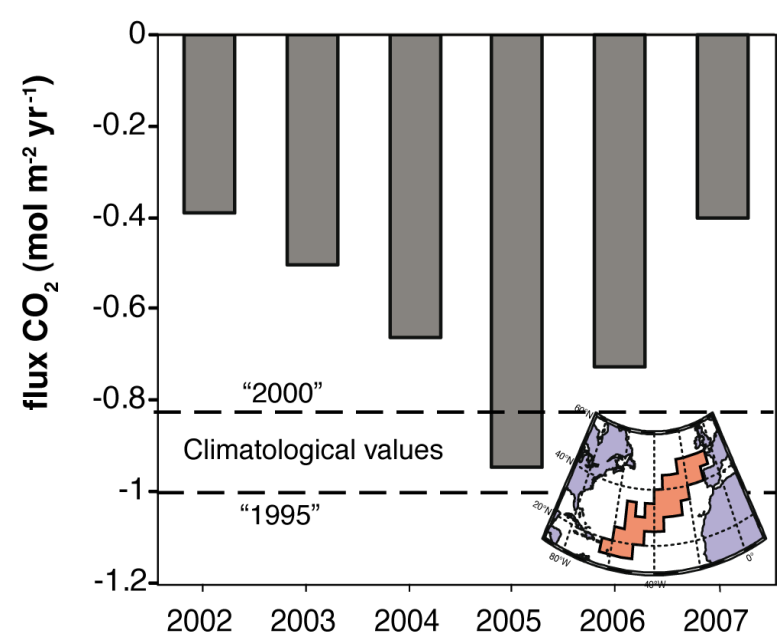

Figure 5: Time-series of the net air-sea $\mathrm{CO}_{2}$ flux in the eastern North Atlantic (see map in inset). Adapted from

[37].

\subsection{Decadal variability in the ocean's interior}

Until today, ship-based hydrography has remained the only method for obtaining high-quality measurements with high spatial and vertical resolution of a wide range of physical, chemical, and biological parameters over the full ocean water column, and in areas of the ocean inaccessible to other platforms. In particular, no other platform is available to observe changes in the deep ocean, below $2000 \mathrm{~m}$, which accounts for $52 \%$ of the ocean volume. Despite the tremendous advances in other observational approaches, classical hydrography has not become obsolete owing to these unique properties.

Following the success of the WOCE/JGOFS global hydrographic survey, which among numerous other important outcomes provided the basis for the globalscale inventory of anthropogenic $\mathrm{CO}_{2}$ in the ocean [29]; a repeat hydrography program for carbon and carbonrelevant parameters was mounted under the umbrella of the 15-year CLIVAR program with coordination through the IOCCP. Following a post-WOCE period characterized by lack of formal global organization and perhaps visibility, the Global Ocean Ship-based Hydrographic Investigations Program (GO-SHIP http://www.go-ship.org/) was launched to develop a sustained hydrographic section program that is part of the Global Ocean Observing System (GOOS) and transcends the limited lifetime of specific research programs [17].

The global repeat survey is carried out with a select subset of WOCE hydrographic sections. The first global repeat survey is presently to about $80 \%$ completed and will be finished in the next few years. The second global survey is scheduled to begin in 2012. First results show profound secular change in ocean properties ranging, for example, from warming and freshening, via increasing storage of total/anthropogenic carbon causing ocean acidification (Fig. 6, [42]; see also [43]) to widespread ocean deoxygenation [10].). These trends are superimposed on large natural variability on a wide range of time scales. Of these, sub-decadal/decadal variability associated with the North Atlantic Oscillation (NAO), the Pacific Decadal Oscillation (PDO), or the Southern Annular Mode (SAM) are most prominent examples. These results clearly illustrate the benefits of decadal hydrographic surveys in providing scientists the opportunity to assess the expected oceanic changes and to use the high-accuracy measurements to evaluate measurements from observing system elements that do not have yet the desired accuracy and/or long-term stability. Furthermore, there are strong synergies of this approach with the other observing system elements, such as the Volunteer Observing Ship Program (3.1), the Argo profiling float (Global array of free-drifting profiling floats) program (3.3), and the time-series stations, all providing highly complementary information.
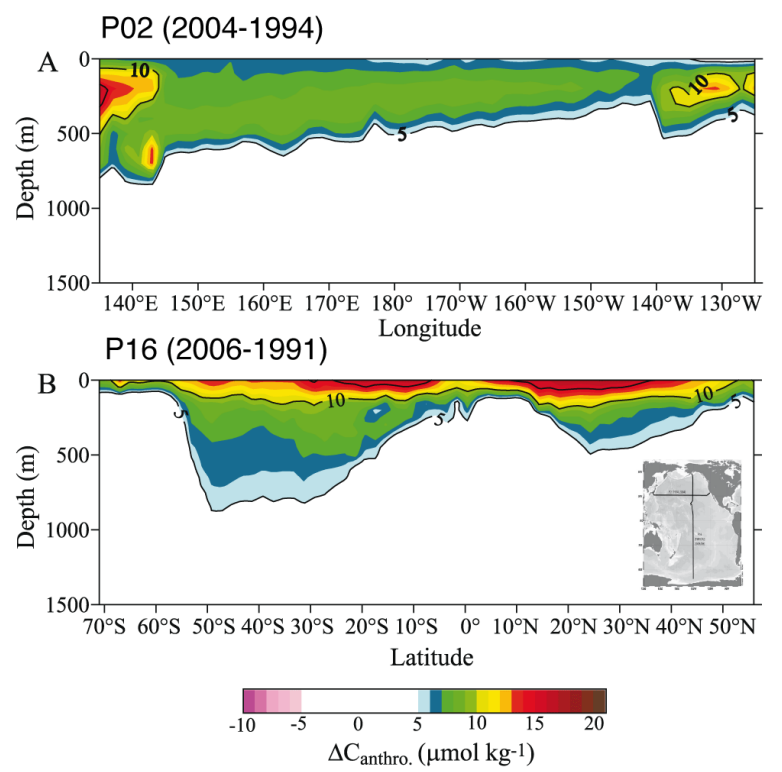

Figure 6: Change in anthropogenic $\mathrm{CO}_{2}$ along two long sections in the Pacific Ocean. (a) Change in anthropogenic $\mathrm{CO}_{2}$ along the zonal section $\mathrm{PO} 2$ in the North Pacific between 1994 and 2004. (b) Change in anthropogenic $\mathrm{CO}_{2}$ along the meridional section $\mathrm{P} 16$ in the central Pacific between 1991 and 2006.

Anthropogenic $\mathrm{CO}_{2}$ was determined using an eMLR approach. See map inset for locations of the cruises. Modified from [42].

\subsection{A synoptic view of the ocean's biogeochemical} variability

Since OceanObs'99, the very successful Argo float program has become an important source of data for many studies, providing for the first time a global synoptic observatory for the ocean's upper $1000 \mathrm{~m}$ [44] 
and [45]. The development of float and sensor technology now provides observational capabilities that were not even contemplated when Argo was created a decade ago. Among the many different measurements made from sensors tested on profiling floats (e.g., wind, rainfall, oxygen, nitrate, bio-optical properties etc., see also [46]) oxygen is perhaps the most advanced and promising candidate for inclusion into the Argo mission [47] and [48]. There are many scientific reasons for undertaking detailed global-scale measurements of the temporal evolution of the ocean's oxygen distribution ([47]). The widespread phenomenon of ocean deoxygenation [10]. as discovered by classical hydrographic surveys (3.2) in itself provides a strong research imperative for the biogeochemical community. To date, over 200 floats with oxygen sensors have been deployed resulting in new scientific insights into the interplay between physics, chemistry, and biology in the ocean (Figure 7, [49] and [50]) as well as methodological insights into the possibilities and current limitations of float-based oxygen measurements [51].
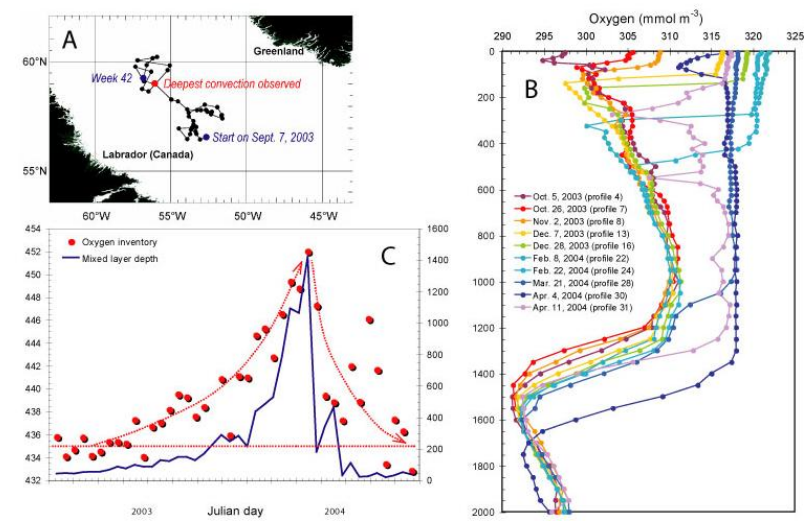

Figure 7 (a) Float track in the central Labrador Sea Gyre, showing positions of weekly surfacing between deployment on 7 September 2003 and profile 42 on 26 June 2004. (b) Selected vertical oxygen profiles. (c) Temporal development of the oxygen inventory (in the upper $1400 \mathrm{~m}$ ) and mixed-layer depth, based on 42 weeks of measurements. Dotted red lines represent the build-up and decay of the oxygen inventory in the convection region relative to an assumed background concentration of the surrounding waters. From [49].

More recently, nitrate and bio-optical sensors have made great advances as well, making it possible to study many crucial oceanic processes, such as the supply of nitrate from the thermocline into the upper ocean [52]. This highlights the great potential of the Argo float platform for building new observing networks (see e.g. [46]).

\subsection{Data assimilation in ocean biogeochemistry}

The last few years have seen the advent of various methods to merge biogeochemical observations and models in order to provide optimal estimates for certain properties, fluxes, and rates (c.f. [53]). These approaches include the use of a Green's function approach to use ocean interior carbon data to constrain air-sea $\mathrm{CO}_{2}$ fluxes of both natural and anthropogenic $\mathrm{CO}_{2}$. This approach naturally links the ocean interior with the surface ocean based networks. In fact, a recent comparison between the two fully independent estimates revealed a remarkable level of agreement, with the exception of the region south of about $30^{\circ} \mathrm{S}$ (Fig. 8).

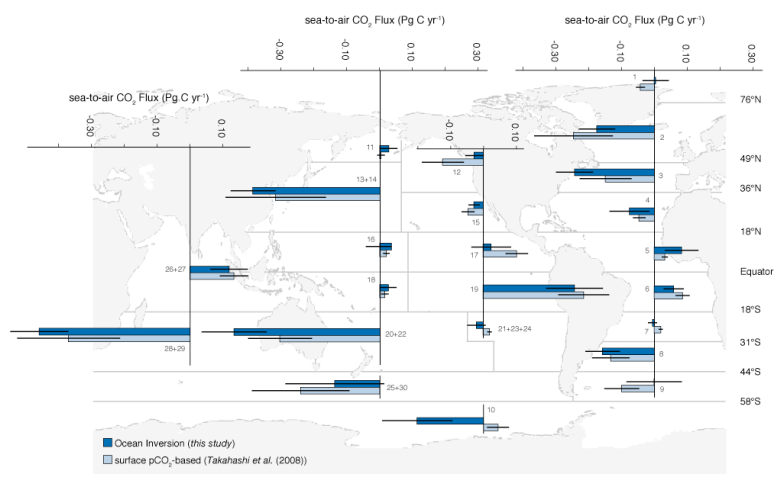

Figure 8: Comparison of the contemporary air-sea $\mathrm{CO}_{2}$ flux between the $\mathrm{pCO}_{2}$ based estimate of [22]. and the ocean inversion-based estimate of [54]. Adapted from

[54].

Other approaches based on Kalman filters [55], adjoint methods [56], and many other techniques have been developed, especially with regard to assimilating surface ocean chlorophyll (c.f. 53]), but data limitations and the complexity arising from the interactions of physics, biogeochemistry, and ecology have prevented rapid progress. Novel statistical methods that combine observations non-linearly may help to overcome some of these limitations (e.g. [57]), but are ultimately limited to interpolating the data, thus having limited predictive capability.

\section{THE WAY FORWARD: THE NEXT DECADE OF OBSERVING OCEAN CARBON AND BIOGEOCHEMISTRY}

\subsection{Introduction}

The fundamental changes in ocean biogeochemistry that are already under way, and the much more profound changes that likely are looming ahead, require a concerted effort in order to determine, understand, and predict these changes and possible feedbacks. Both the changes in the ocean's carbon cycle associated with the uptake of anthropogenic $\mathrm{CO}_{2}$ from the atmosphere and the additional changes expected from the interactions of the natural carbon cycle with climate justify the continuation and extension of the ocean carbon observing networks. But also the more recently recognized biogeochemical changes associated with 
ocean acidification and the loss of oxygen (deoxygenation) warrant attention, as their impacts on marine ecosystems and services might be substantial. Finally, potential changes in the ocean's nutrient inventory and supply to the surface might alter ocean primary production with a myriad of cascading effects.

Thus, an observing network for ocean biogeochemistry has the following specific objectives:

\subsection{Objectives}

The objectives are to determine, understand, and predict the past, present, and future

- $\quad$ oceanic sink for anthropogenic $\mathrm{CO}_{2}$;

- changes in the oceanic carbon system resulting from climate change, and ocean acidification;

- changes in dissolved oxygen and other important biogeochemical elements.

The biogeochemical changes occur globally requiring that these objectives need to be met on a global level. Regional differences are expected, however, justifying regionally enhanced efforts, such as in coastal regions (see e.g. [58]). Identifying and achieving the measurement accuracy required to meet the scientific goals needs special attention and forms an essential part of the observation network. For example, in its implementation plan, the IMBER-SOLAS (Integrated Marine Biogeochemistry and Ecosystem Research Project/ Surface Ocean - Lower Atmosphere Study) joint research group on the ocean carbon cycle states that it aims to determine the oceanic uptake, transport, and storage of anthropogenic $\mathrm{CO}_{2}$ with an accuracy of

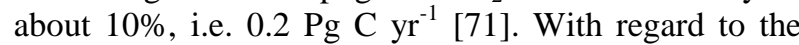
surface ocean carbon fluxes, IMBER-SOLAS specified an objective of "constraining net annual oceanatmosphere $\mathrm{CO}_{2}$ flux at the scale of an ocean basin to $<0.2 \mathrm{Pg} \mathrm{C} \mathrm{yr}^{-1}$ " while [21] suggest a relative accuracy of “ $\pm 10-15 \%$ of the annual mean flux".

\section{IMPLEMENTATION}

\subsection{Preamble}

The proposed integrated network to address the above objectives consists of a combination of well-tested and new emerging elements. Together, they will bring a step change in our ability to observe the biogeochemical changes that will be occurring in the coming decades. They will also provide the required measurements to assess critical societal questions such as a full assessment of the global redistribution of the $\mathrm{CO}_{2}$ emitted into the atmosphere as a consequence of fossil fuel burning and land-use change. With the potential advent of a global $\mathrm{CO}_{2}$ emission regulation system with an associated price for $\mathrm{CO}_{2}$, the need for the ability to undertake a proper accounting of the emitted $\mathrm{CO}_{2}$ will become paramount.

In particular, the following elements are envisioned:

- Surface ocean network

- Interior ocean network

- Time-series stations network

- Lagrangian network

Data from these observing systems need to be subjected to careful quality control and data assembly procedures, requiring dedicated support of such facilities. Sustained synthesis activities involving also novel data-model integration approaches are envisioned to realize the complimentary strengths of the four main observing elements. Finally, dedicated efforts are needed to realize the full potential of newly emerging technological approaches, particularly with regard to the development and deployment of stable, low-power sensors on Lagrangian platforms.

\subsection{Surface ocean network}

The primary means for observing the air-sea fluxes of $\mathrm{CO}_{2}$ (objectives 1 and 2) is a surface ocean network built on the existing collaborative SOOP network. Thus, the sustaining and extension of this network is critical, since only through a continuation of this large international effort will new insight into scales of variability and its driving physical and/or biological factors be gained. Autonomous moored $\mathrm{CO}_{2}$ systems are beginning to augment the ship-based measurements, but the network is still in its infancy and needs to be greatly expanded (see also [36]).

Moving forward, the first priority is to maintain the existing network, whose funding has not been stable through time, causing many observing elements to come and go. The second priority is to fill the many still existing gaps in space and time (see also Fig. 4). This can be achieved by fostering the establishment of additional SOOP lines and moorings in undersampled regions in a coordinated and strategic way. [21] suggest an intensification of the observing network to a net density of about 3-monthly sampling at a spatial resolution of about $3-6^{\circ}$ meridionally and $10-30^{\circ}$ zonally depending on the ocean basins. This density was based on some preliminary observing system design criteria, and needs to be re-evaluated using more complete system design studies.

These proposed minimum surface $\mathrm{CO}_{2}$ sampling scheme, depicted in Fig. 9 superimposed on the present SOOP activity, provide an indication of the gap between existing and required sampling to achieve the vision set out by [21]. Areas of high variability, such as the coastal ocean, will require higher frequency sampling, part of 
which can be achieved by benefiting from targeted coastal surveys, ferries and moorings (see [58]).

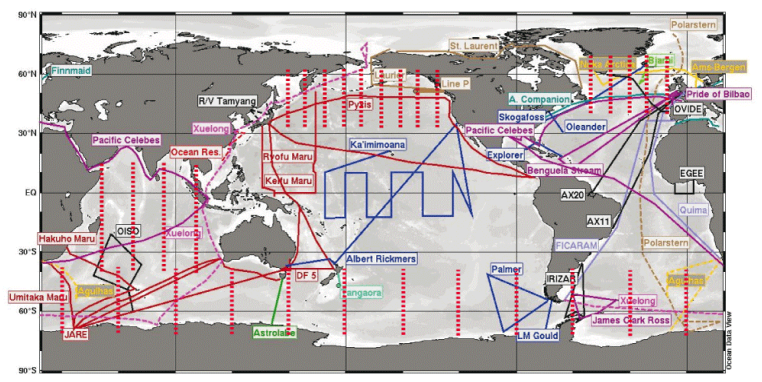

Figure 9: Map showing the recommended spatial sampling density for the surface ocean network (red dots) superimposed on the existing SOOP-based network. In order to reach the stated objectives, each location would have to be sampled roughly 4-times a year. From [21].

Such an extension of the SOOP network, however, is challenging in regions where commercial shipping routes are absent (e.g. Southern Ocean, tropical southeast Pacific). Here, the $p \mathrm{CO}_{2}$ observatory can only be extended by integration of other autonomous platforms such as moorings and surface drifters. While this is now reasonably feasible with existing sensor and platform technology even under harsh environmental conditions ([59] and [60]), the technology is expensive and only suitable for surface measurements, i.e. it cannot be deployed on instruments that dive to depths. A major focus therefore needs to be placed on the development and improvement of suitable $\mathrm{CO}_{2}$ sensors employing novel technologies. A big advantage is that the resulting network will allow us to simultaneously address carbon cycle and ocean acidification research priorities with one observing system [5] and [61]).

\subsection{Interior ocean network}

Long-term changes in the ocean's interior biogeochemistry below the upper $20 \mathrm{~m}$ are currently accessible only by a ship-based observing approach or moorings (see [17].). This is particularly the case for the documentation of the long-term changes of the ocean carbon system, for which there does not (yet) exist suitable sensors for long-term deployment on Lagrangian floats. Thus, in order to determine the oceanic uptake, transport, and storage of anthropogenic $\mathrm{CO}_{2}$ in the ocean (objective 1), and for documenting the long-term changes in the ocean's oxygen and carbonate systems, (particularly in the deep ocean below the reach of most Lagrangian floats,) (objective 2), regular research ship-based surveys with a set of highly standardized measurements are needed [62].
To reach these objectives, [17] suggest an observing program with a roughly 10 year repeat cycle with several meridional and zonal cruises per basin (Fig. 10, see also www.go-ship.org/)

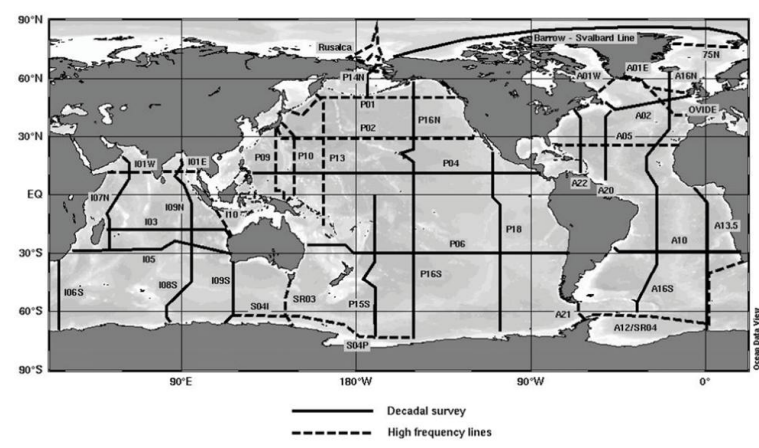

Figure 10: Map showing the recommended spatial sampling density for the interior ocean network. A temporal sampling frequency of 10 years is

recommended for the decadal survey sections (solid), while the high-frequency sections should be re-sampled every two to three years. From [17].

This shipboard-based approach for determining longterm changes in the ocean's biogeochemistry benefits strongly from the many synergies that can be realized with the wealth of additional parameters that can be measured from a ship, especially the large suite of physical and biogeochemical tracers (e.g. CFCs (chlorofluorocarbons), radiocarbon and other isotopes) as well as the organic components of the ocean carbon cycle (particulate and dissolved organic carbon). Particularly relevant in this respect for the coming decade is also the large potential for synergies with the GEOTRACES program (www.geotraces.org).

\subsection{Time-series Stations}

The gap in space and time that emerges between the upper ocean and the interior ocean observing systems can be optimally filled with a time-series station approach, which builds on the successful time-series programs that have been established at a handful of places around the world. In this approach, a suite of sites is sampled at relatively high frequency and throughout the full water column using a combination of moorings and ship-based surveys. For the open ocean, this approach has been organized through the OceanSITES (OCEAN Sustained Interdisciplinary Time series Environment Observation System ) initiative (see: www.oceansites.org, [63] and [36]), while no such coordinated effort exists for the coastal ocean, though this is highly recommended (see [58]).

Particular strengths of the time-series approach are its ability to focus on the processes driving the observed 

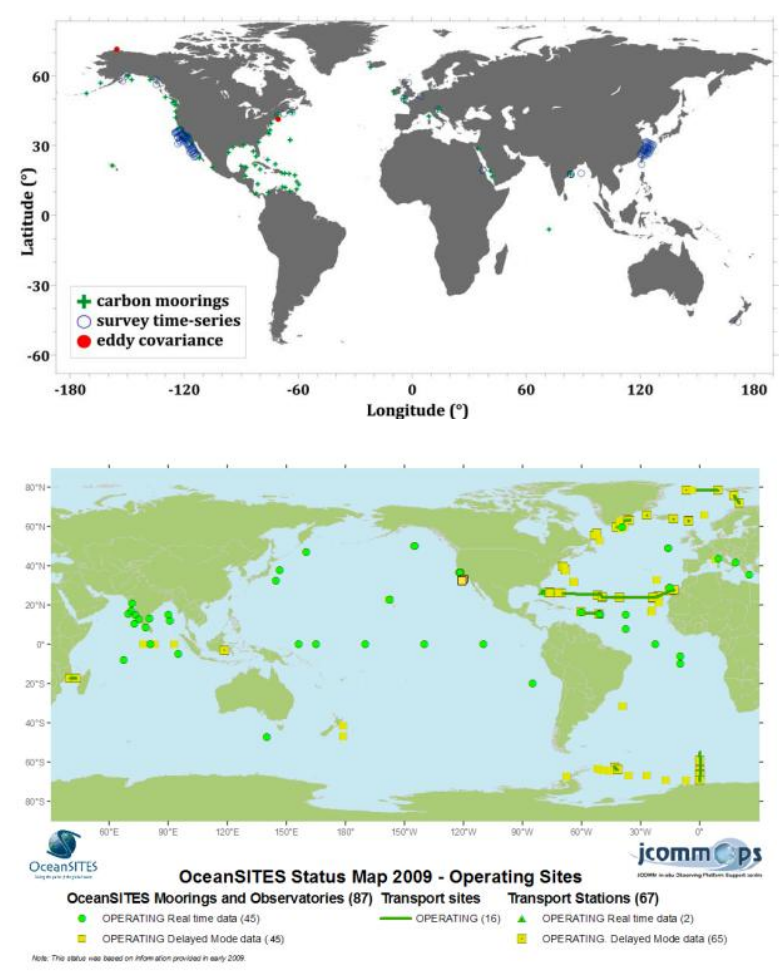

Figure 11: Map showing the current status of (a) coastal and (b) open ocean time-series sites. In (b) only those stations from the TAO/TRITON/PIRATA/RAMA (Tropical Atmosphere Ocean/Triangle Trans-Ocean Buoy Network/Prediction and Research Moored Array in the Atlantic/Moored Array for African-Asian-

Australian Monsoon Analysis and Prediction) arrays are shown that include biogeochemical measurements. From [58] and [36].

changes as well as the possibility of obtaining measurements across the entire frequency domain of interest, e.g. from seconds to years. Time-series sites are also ideal testbeds for new approaches and instruments, including the possibility of measuring the air-sea flux of $\mathrm{CO}_{2}$ directly using eddy co-variance methods.

\subsection{Lagrangian Observation Systems}

A Lagrangian observing system of sufficient spatial and temporal density represents an almost ideal system for observing upper ocean biogeochemical variability on seasonal to interannual time-scales. However, the lack of suitable sensors has limited this approach so far mostly to oxygen and bio-optics (see e.g. [47]) for an Argo-based oxygen program and the [46] for a biooptical Argo program). Additional sensors, such as nitrate [52]. and $\mathrm{pH}$ are making rapid progress as well, eventually permitting to extend Lagrangian observing systems to a much larger suite of parameters (cf. [48]).

Both programs suggest a multi-phase implementation with a pilot phase followed by a fully-fledged (global) deployment of the observing system. The details of such a pilot phase still need to be defined. An important question that needs to be addressed is the regional focus of the pilot study that provides for scientifically interesting spatio-temporal dynamics, the possibility for ground-truthing exercises through existing hydrographic survey and time series, the existence of prior data and system understanding, and finally a large range in the target variables.

Following and building on the results of a successful pilot phase, a global implementation of the Argo-based programs is envisioned. Although detailed analyses has not yet been carried out, de-correlation length scales for oxygen could be expected to be similar to those of temperature, possibly requiring the entire Argo observatory of $\sim 3.000$ floats to be equipped with oxygen sensors. [46] suggests that for a bio-optical float program, equipping about every fifth float could be sufficient.

Global float-based oxygen and/or bio-optical observatories will provide much insight into ocean climate change and biogeochemistry, thereby helping to understand also the dynamics and changes in the ocean's carbon system. Eventually, however, direct carbon observations from floats are desired. This is currently not feasible because of the lack of carbon sensors meeting the stringent requirements for float applications. Membrane-based $p \mathrm{CO}_{2}$ sensors have been tested on floats (Körtzinger, pers. comm.). The results are promising but limited so far by the comparatively long time constants of available $p \mathrm{CO}_{2}$ sensor technology. Sensors for $\mathrm{pH}$ that are based on ionsensitive field effect transistor (ISFET) technology and capable of long-term operation, are now being tested in the laboratory and on surface moorings where they show great potential for future float applications [64]. In any case, the Argo-Oxygen and the Argo based biooptics program will provide the operational knowledge and tools to implement a possible future Argo-Carbon program, which despite promising first results is beyond the 10-year scope of this paper.

Gliders, of which more than $\sim 100$ are now being operated, represent a further development of the floats' buoyancy engine technology. Gliders combine profiling measurements with the possibility to follow a predetermined path. Although gliders are strictly speaking not Lagrangian platforms, they have similar requirements for sensors. Glider observations could be nested into a float array where high spatio-temporal resolution and/or a narrow regional focus is required or where float observations need to be extended horizontally, e.g. towards the continental slope or onto the shelves as currently being envisioned, for example, by the U.S. Ocean Observatories Initiative's Pioneer array. 


\subsection{Technological Advances}

A common trait of most observational approaches is their current limitation by the availability of sensors and systems for in situ observations of marine carbon dioxide system variables [65]. Depending on the observational platform under consideration, different parameters of the $\mathrm{CO}_{2}$ system may be of highest interest and very different requirements for sensors/systems emerge. It is obvious, for example, that high quality $p \mathrm{CO}_{2}$ measurements from a SOOP are much easier to implement than from a surface drifter or even a profiling float. The stage of development is therefore vastly different for the various applications:

- For SOOP operations, elaborate and reliable $p \mathrm{CO}_{2}$ systems with classical gas-water equilibration and subsequent NDIR $\mathrm{CO}_{2}$ detection are available and will not be further considered here (see ioccp.org for details).

- For Lagrangian surface drifters, $p \mathrm{CO}_{2}$ systems based on a colorimetric method that are fully integrated into drifter systems are commercially available (e.g., CARIOCA (Carbon Interface Ocean Atmosphere buoy) system: [66]) and have provided high-quality data even under harsh environmental conditions (e.g., [59]).

- For Eulerian sub-surface observations (moorings), $p \mathrm{CO}_{2}$ and $\mathrm{pH}$ sensors with long endurance and good precision are commercially available (e.g., $\mathrm{MAPCO}_{2}$ (Moored Autonomous Partial Pressure Carbon Dioxide) system, SAMI (Submersible Autonomous Moored Instrument) system: [67]) and also have provided high-quality data even under difficult environmental conditions (e.g., [68]). However, failures and instrument drift together with the lack of means of standardization remain an issue with these first-generation of in situ instruments.

- For Langrangian platforms (profiling floats, gliders) currently no fully suitable carbon sensor is available. First tests with membrane-based $p \mathrm{CO}_{2}$ sensors show some promise but also major shortcomings. For $\mathrm{pH}$, the emerging ISFET technology holds significant promise, but again, major work has to be done before such sensors are operational for sub-surface Lagrangian platforms [64].

With autonomous platforms making impressive progress, the need for carbon sensors akin to the oxygen optode (i.e. being small in size and robust, requiring low power, having long-term stability and high precision) is becoming more and more pressing. Major emphasis should therefore be placed on sensor development. This includes both the improvement of existing methods and systems for higher performance and the introduction of new technologies. Special consideration must be given to the rigorous assessment of precision and accuracy as well as long-term stability.

Also the development of sensors for other critical parameters needs to be pushed forward, particularly for nutrients and various optical properties (see [46]).

\subsection{Data requirements, assembly \& syntheses}

Well established data quality procedures and data centers that can provide support for data management and data services are as much the backbone for an ocean carbon and biogeochemical observing system as they are for any other ocean observing system [69]. For most biogeochemical applications, especially those undertaken to reach the objectives set out in 4.2 , the data do not have to be provided to the larger community in real time, i.e. a delayed data mode approach is currently deemed sufficient. Since the primary objectives are about the observation and characterization of seasonal and longer-term changes in the ocean's biogeochemistry, ensuring the highest data quality is the primary objective.

Data assembly and initial quality control procedures have already been developed for the surface and Interior Ocean networks, while such procedures are in development for the Lagrangian networks. It is recommended that these successful data assembly centers in the respective networks are sustained and equipped to handle the biogeochemical data.

The accurate determination of long-term changes often requires secondary data control procedures, which need to be supported and sustained as well.

\subsection{Model and data integration}

The expansion of the observing networks for ocean biogeochemistry (and also for bio-optics, see [46] opens great potential for moving this field from a data-limited into a data-rich era, providing excellent opportunities for making a big step forward with regard to the use of models to synthesize data, and to develop and apply sophisticated data-model fusion procedures, i.e., data assimilation similar to those used for ocean physics. In particular, such procedures will permit researchers to interpret the large amounts of data in their spatial and temporal context, and to turn concentration measurements into quantitative rate estimates over large regions of the ocean. Achieving an integrated system will require substantial effort in this area. Some of the proposed pilot studies would represent ideal vehicles for making rapid progress.

\subsection{Integration across observing elements}

In principle, the different observational approaches can be regarded as stand-alone initiatives with their own rationales, objectives, analysis tools and synthesis products. In fact, this has been the path followed historically, even though many are often involved in 
more than one approach. Overcoming this separation is a major objective for the biogeochemistry community for the next decade.

Clearly, the various approaches probe the marine carbon cycle and ocean biogeochemistry from different perspectives but they still study the same entity. A good example is the surface ocean network that aims to pin down the net air-sea flux of $\mathrm{CO}_{2}$ on a global grid at monthly resolution as precisely as possible. Any regional net $\mathrm{CO}_{2}$ sink/sources, however, by necessity have to match changes in the interior ocean carbon storage and/or regional carbon transport divergences. Thus, the surface and interior ocean network elements are providing important complementary information and provide a powerful means to assess inconsistencies that in turn lead to scientific insights. Atmospheric $\mathrm{CO} 2$ observatories (e.g. GLOBALVIEW-CO2 (Cooperative Atmospheric Data Integration Project) could also be expanded by integrating measurements from ocean observatories (SOOP, etc...) to expand data coverage and provide additional constrains to atmospheric inversion models.

The combination of time series, surface and interior observing elements also makes for an optimal description of regional carbon characteristics and dynamics. Eulerian time-series can provide high temporal and vertical resolution (1-D), which allows us to observe and identify the necessary scales of temporal variability and reliably detect secular trends. A surface ocean SOOP line that ideally would run through a timeseries location would benefit greatly from the understanding of surface ocean dynamics gained at the time-series but at the same time put the latter into a larger regional context. Mechanistic understanding derived from time-series observations could thus be set in a regional context. As a further example, a strong case can be made that the spatio-temporal distribution of oxygen observed by a full Argo-Oxygen program will aid in the interpretation of sparse data from repeat hydrographic surveys.

These examples document the need to coordinate the observational systems and foster synthesis efforts that combine the data from the different systems. This way, synergies can be achieved on issues such as the assessment of data quality and consistence, the complementarity of spatial and temporal resolution and coverage, or independent proof of fundamental understanding. It is worthwhile to note that this complementarity not only applies to the observation systems described here but also to other existing observatories, e.g. the strong link between an ArgoOxygen program and the atmospheric oxygen network, which could improve the atmospheric $\mathrm{O}_{2} / \mathrm{N}_{2}$ constraint on the oceanic uptake of anthropogenic $\mathrm{CO}_{2}[10]$.

\section{CONCLUSION}

The fundamental changes in ocean biogeochemistry that we expect to occur for the 21 st century as well as the large challenges associated with a full accounting of the fate of anthropogenic $\mathrm{CO}_{2}$ leave us no option but to renew and expand our efforts to observe the ocean's carbon cycle and biogeochemistry. Time-tested approaches and technologies are ready to meet this challenge. But also new technologies and approaches need to be pushed strongly opening new doors permitting us to make a step change in observation and understanding.

These efforts cannot and should not occur in isolation, but in close collaboration with the other observing elements of the ocean, in particular those focusing on the ocean's physical state and those focusing on transport and mixing. Many synergies can also be expected with the emerging observing capabilities for ocean ecosystems (e.g. [46].

\section{REFERENCES}

1. Sarmiento, J.L. and N. Gruber (2002). Sinks for anthropogenic carbon, Physics Today, 55(8), 30-36.

2. Doney, S.C., V.J. Fabry, R.A. Feely, J.A. Kleypas (2009): Ocean acidification: the other $\mathrm{CO}_{2}$ problem, Ann. Rev. Mar. Sci., 1, 169-192.

3. Riebesell, U., A. Körtzinger, and A. Oschlies (2009). Sensitivities of marine carbon fluxes to ocean change. Proc. Natl. Acad. Sci. USA 106, 20602-20609.

4. Feely, R.A., Boutin, J., Cosca, C.E., Dandonneau,Y., Etcheto, J., Inoue, H., Ishii, M., Le Quéré, C., Mackey, D.J., McPhaden, M., Metzl, N., Poisson, A. \& Wanninkhof, R. (2002). Seasonal and interannual variability of $\mathrm{CO}_{2}$ in the equatorial Pacific. Deep-Sea Res. II, 49, 2443-2469.

5. Iglesias-Rodriguez, M. \& Co-Authors (2010). "Developing a Global Ocean Acidification Observation Network" in these proceedings (Vol. 1), doi:10.5270/OceanObs09.pp.24.

6. Riebesell, U., I. Zondervan, B. Rost, P.D. Tortell, R.E. Zeebe, and F.M.M. Morel (2000). Reduced calcification of marine plankton in response to increased atmospheric $\mathrm{CO}_{2}$. Nature 407, 364-367.

7. Orr, J. C., et al., Anthropogenic ocean acidification over the twenty-first century and its impact on calcifying organisms, Nature 437, 681-686, doi:10.1038/nature04095.

8. Feng, Y., M.E. Warner, Y. Zhang, J. Sun; F.-X. Fu, J.M. Rose, D.A. Hutchins (2008). Interactive effects of increased $p \mathrm{CO}_{2}$, temperature and irradiance on the marine coccolithophore Emiliania huxleyi (Prymnesiophyceae). Eur. J. Phyc. 43, 87-98. 
9. Iglesias-Rodriguez, M.D., P. R. Halloran, R.E.M. Rickaby, I.R. Hall, E. Colmenero-Hidalgo, J.R. Gittins, D.R.H. Green, T. Tyrrell, S.J. Gibbs, P. von Dassow, E. Rehm, E.V. Armbrust, K.P. Boessenkool (2008). Phytoplankton calcification in a high- $\mathrm{CO}_{2}$ world. Science 320, 336-340.

10. Keeling RF, Kortzinger A, Gruber N. (2010). Ocean deoxygenation in a warming world. Ann Rev Mar Sci 2: 199-229, doi:10.1146/annurev.marine.010908.163855.

11. Naqvi S. W. A., H. W. Bange, L. Farías, P. M. S. Monteiro, M. I. Scranton, and J. Zhang (2009) Coastal hypoxia/anoxia as a source of $\mathrm{CH} 4$ and $\mathrm{N} 2 \mathrm{O}$, Biogeosciences, 7, doi:10.5194/bg-7-21592010.

12. Gruber, N., and J. N. Galloway (2008), An Earth system perspective on the global nitrogen cycle, Nature, 451, 293-296, doi:10.1038/nature06592.

13. Galloway, J. N. et al. (2004). Nitrogen cycles: past, present, future. Biogeochemistry 70, 153-226, doi: 10.1007/s10533-004-0370-0.

14. Diaz R.J. and R. Rosenberg (2008). Spreading Dead Zones and Consequences for Marine Ecosystems. Science 321: 926-929, doi: 10.1126/science.1156401.

15. Krishnamurthy, A., J. K. Moore, N. Mahowald, C. Luo, S. C. Doney, K. Lindsay, and C. S. Zender (2009), Impacts of increasing anthropogenic soluble iron and nitrogen deposition on ocean biogeochemistry, Global Biogeochem. Cycles, 23, GB3016, doi:10.1029/2008GB003440.

16. Doney, S.C. (2010). The Growing Human Footprint on Coastal and Open-Ocean Biogeochemistry, Science, 328, 1512, doi:10.1126/science.1185198.

17. Hood, M. \& Co-Authors (2010). "Ship-Based Repeat Hydrography: A Strategy for a Sustained Global Program." in these proceedings (Vol. 2), doi:10.5270/OceanObs09.cwp.44.

18. Siegenthaler, U. and J.L. Sarmiento (1993). Atmospheric carbon dioxide and the ocean. Nature 365, 119-125, doi: $10.1038 / 365119 \mathrm{a} 0$.

19. Keeling, C.D., N.W. Rakestraw, and L.S. Waterman (1965). Carbon dioxide in surface waters of the Pacific Ocean, 1. Measurements of the distribution. J. Geophys. Res. 70, 6087-6098.

20. Takahashi, T. (1961). Carbon dioxide in the atmosphere and in Atlantic Ocean water. J. Geophys. Res. 66, 477494.

21. Monteiro, P. \& Co-Authors (2010). "A Global Sea Surface Carbon Observing System: Assessment of Changing Sea Surface $\mathrm{CO} 2$ and Air-Sea CO2 Fluxes" in these proceedings (Vol. 2), doi:10.5270/OceanObs09.cwp.64.

22. Takahashi, T., S.C. Sutherland, R. Wanninkhof, C. Sweeney, R.A. Feely, D. Chipman, B. Hales, G. Friederich, F. Chavez, A. Watson, D. Bakker, U. Schuster, N. Metzl, H.Y. Inoue, M. Ishii, T. Midorikawa, C. Sabine, M. Hoppema, J. Olafsson, T. Amarson, B. Tilbrook, T. Johannessen, A. Olsen, R. Bellerby, Y. Nojiri, C.S. Wong, B. Delille, N. Bates and
H. De Baar. (2009). Climatological mean and decadal change in surface ocean $p \mathrm{CO}_{2}$, and net sea-air $\mathrm{CO}_{2}$ flux over the global oceans. Deep-Sea Res II 56, 554-577, doi:10.1016/j.dsr2.2008.12.009.

23. Takahashi, T., R. A. Feely, R. Weiss, R. H. Wanninkhof, D. W. Chipman, S. C. Sutherland, and T. T. Takahashi (1997), Global air-sea flux of $\mathrm{CO}_{2}$ : an estimate based on measurements of sea-air $\mathrm{pCO}_{2}$ difference, Proc. Natl. Acad. Sci., 94, 8292 - 8299.

24. Körtzinger, A., L. Mintrop, D.W.R. Wallace, K.M Johnson, C. Neill, B. Tilbrook, P. Towler, H. Inoue, M. Ishii, G. Shaffer, R.F. Torres, E. Ohtaki, E. Yamashita, A. Poisson, C. Brunet, B. Schauer, C. Goyet, and G. Eischeid (2000). The International At-sea Intercomparison of $f \mathrm{CO}_{2}$ systems during the $\mathrm{R} / \mathrm{V}$ Meteor cruise 36/1 in the North Atlantic Ocean. Mar. Chem. 72: 171-192.

25. Wallace, D.W.R. (2001). Storage and transport of excess $\mathrm{CO}_{2}$ in the oceans: The JGOFS/WOCE global $\mathrm{CO}_{2}$ survey (2001), in: Ocean Circulation and Climate, edited by G. Siedler, J. Church, and J. Gould, Elsevier, New York, pp. 489-521.

26. Key, R.M., A. Kozyr, C.L. Sabine, K. Lee, R. Wanninkhof, J.L. Bullister, R.A. Feely, F.J. Millero, C. Mordy, and T.H. Peng (2004), A global ocean carbon climatology: Results from Global Data Analysis Project (GLODAP), Global Biogeochem. Cycles 18, GB4031, doi:10.1029/2004GB002247.

27. Sabine, C.L., Heimann, M., Artaxo, P., Bakker, D., Chen, C.-T.A., Field, C.B., Gruber, N., Le Quéré, C., Prinn, R.G., Richey, J.E., Lankao, P.R., Sathaye, J. and Valentini, R. (2004a) Current status and past trends of the global carbon cycle. In: Field, C.B. and Raupach, M.R. (eds) The Global Carbon Cycle: Integrating Humans, Climate, and the Natural World. Scope 62, Island Press, Washington, DC, pp. 17-44.

28. Gruber, N., Sarmiento, J.L. and Stocker, T.F. (1996) An improved method for detecting anthropogenic $\mathrm{CO} 2$ in the oceans. Global Biogeochemical Cycles 10, 809-837, doi:10.1029/96GB01608.

29. Sabine C.L., R.A. Feely, N. Gruber, R.M. Key, K. Lee, J.L. Bullister, R. Wanninkhof, C.S. Wong, D.W.R. Wallace, B. Tilbrook, F.J. Millero, T.-H. Peng, A. Kozyr, T. Ono, and A.F. Rios (2004b) The Oceanic sink for anthropogenic $\mathrm{CO}_{2}$. Science 305, 367-371.

30. Keeling, C. D. (1993), Surface ocean $\mathrm{CO}_{2}$, in: Global Carbon Cycle, edited by M. Heimann, Springer, New York, pp. 22-29.

31. Gruber, N., Keeling, C.D. and Bates, N.R. (2002) Interannual variability in the North Atlantic Ocean carbon sink. Science 298(5602), 2374-2378. doi:10.1126/science.1077077

32. Bates, N. R. (1997) Interannual variability of the oceanic $\mathrm{CO}_{2}$ sink in the subtropical gyre of the North Atlantic Ocean over the last 2 decades. J. Geophys. Res., 112, C09013, doi:10.1029/2006JC003759. 
33. Sabine, C.L., F.T. Mackenzie, C. Winn, and D.M. Karl (1995). Geochemistry of carbon dioxide in seawater at Hawaii Ocean Time series station, ALOHA. Global Biogeochem. Cycles 9, 637-651.

34. Dore, J.E., R. Lukas, D.W. Sadler, and D.M. Karl (2003), Climate-driven changes to the atmospheric $\mathrm{CO}_{2}$ sink in the subtropical North Pacific Ocean. Nature 424, 754. 757.

35. Keeling, C.D., H. Brix, and N. Gruber (2004), Seasonal and long-term dynamics of the upper ocean carbon cycle at Station ALOHA near Hawaii, Global Biogeochem. Cycles 18, GB4006, doi:10.1029/2004GB002227.

36. Send, U. \& Co-Authors (2010). "OceanSITES" in these proceedings (Vol. 2), doi:10.5270/OceanObs09.cwp.79.

37. Watson, A.J., U. Schuster, D.C.E. Bakker, N.R. Bates, A. Corbière, M. González-Dávila, T. Friedrich, J. Hauck, C. Heinze, T. Johannessen, A. Körtzinger, N. Metzl, J. Olafsson, A. Olsen, A. Oschlies, X.A. Padin, B. Pfeil, J.M. Santana-Casiano, T. Steinhoff, M. Telszewski, A.F. Rios, D.W.R. Wallace, and R. Wanninkhof (2009). Tracking the variable North Atlantic sink for atmospheric $\mathrm{CO}_{2}$. Science 326, 1391-1393.

38. Le Quéré, C., T. Takahashi, C. E. Buitenhuis, C. Rödenbeck, and S. Sutherland (2010). Impact of climate change on the global oceanic sink of $\mathrm{CO} 2$. Global Biogeochemical Cycles, 24, GB4007. doi:10.1029/2009GB003599.

39. Le Quéré, C., C. Rödenbeck, E.T. Buitenhuis, T. J. Conway, R. Langenfelds, A. Gomez, C. Labuschagne, M. Ramonet, T. Nakazawa, N. Metzl, N. Gillett, and M. Heimann (2007) Saturation of the Southern ocean $\mathrm{CO}_{2}$ sink due to recent climate change, Science, 316, doi:10.1126/science.1136188, 1735-1738.

40. Lovenduski, N. S., N. Gruber, S. C. Doney and I. D. Lima, (2007) Enhanced $\mathrm{CO}_{2}$ outgassing in the Southern Ocean from a positive phase of the Southern Annular Mode, Global Biogeochemical Cycles, 21, GB2026, doi:10.1029/2006GB002900.

41. Metzl, N. (2009). Decadal increase of oceanic carbon dioxide in Southern Indian surface ocean waters (19912007). Deep Sea Res. II, doi:10.1016/j.dsr2.2009.01.002.

42. Sabine, C.L., R.A. Richard, F.J. Millero, A.G. Dickson, C. Langdon, S. Mecking, and D. Greeley (2008). Decadal changes in Pacific carbon. J. Geophys. Res. 113, C07021, doi:10.1029/2007JC004577,

43. Sabine, C.L. and T. Tanhua (2010). Estimation of anthropogenic $\mathrm{CO}_{2}$ inventories in the ocean. Ann. Rev. Mar. Sci. 2, 175-198.

44. Freeland, H. \& Co-Authors (2010)."Argo - A Decade of Progress" in these proceedings (Vol. 2), doi:10.5270/OceanObs09.cwp.32.

45. Roemmich, D. \& Co-Authors (2010). "Integrating the Ocean Observing System: Mobile Platforms" in these proceedings (Vol. 1), doi:10.5270/OceanObs09.pp.33.

46. Claustre, H. \& Co-Authors (2010). "Bio-Optical Profiling Floats as New Observational Tools for Biogeochemical and Ecosystem Studies: Potential Synergies with Ocean Color Remote Sensing." in these proceedings (Vol. 2), doi:10.5270/OceanObs09.cwp.17.

47. Gruber, N. \& Co-Authors (2010). "Adding Oxygen to Argo: Developing a Global In Situ Observatory for Ocean Deoxygenation and Biogeochemistry" in these proceedings (Vol. 2), doi:10.5270/OceanObs09.cwp.39.

48. Johnson, K.S., W.M. Berelson, E.S. Boss, Z. Chase, H. Claustre, S.R. Emerson, N. Gruber, A. Körtzinger, M.J. Perry, and S.C. Riser (2009). Observing biogeochemical cycles at global scales with profiling floats and gliders: prospects for a global array, Oceanography 22, 217-225.

49. Körtzinger, A., J. Schimanski, U. Send, and D.W.R. Wallace (2004). The ocean takes a deep breath. Science 306, 1337.

50. Riser, S.C. and K.S. Johnson (2008) Net production of oxygen in the subtropical ocean, Nature $\mathbf{4 5 1}$, doi:10.1038/nature06441, 323-325.

51. Körtzinger, A., J. Schimanski, and U. Send (2005). Highquality oxygen measurements from profiling floats: A promising new technique. J. Atm. Ocean. Techn. 22, 302-308.

52. Johnson, K. S., S.C. Riser and D. M. Karl (2010). Nitrate supply from deep to near-surface waters of the North Pacific subtropical gyre, Nature 465, doi: 10.1038/nature09170, 1062-1065.

53. Brasseur, P., N. Gruber, R. Barciela, K. Brander, M. Doron, A. El Moussaoui, A. J. Hobday, M. Huret, A.-S. Kremeur, P. Lehodey, C. Moulin, R. Murtugudde, I. Senina, E. Svendsen, R. Matear (2009) Integrating biogeochemistry and ecology into ocean data assimilation systems, Oceanography, 22(3), 192-201.

54. Gruber, N., M. Gloor, S.E. Mikaloff Fletcher, S.C. Doney, S. Dutkiewicz, M.J. Follows, M. Gerber, A.R. Jacobson, F. Joos, K. Lindsay, D. Menemenlis, A. Mouchet, S.A. Müller, J.L. Sarmiento, and T. Takahashi (2009). Oceanic sources, sinks, and transport of atmospheric $\mathrm{CO}_{2}$. Global Biogeochemical Cycles, 23, GB1005, doi:10.1029/2008GB003349.

55. Gerber, M., F. Joos, M. Vázquez-Rodríguez, F. Touratier, and C. Goyet (2009). Regional air-sea fluxes of anthropogenic carbon inferred with an Ensemble Kalman Filter. Global Biogeochem. Cycles 23, GB1013, doi:10.1029/2008GB003247.

56. Schlitzer, R. (2002), Carbon export fluxes in the Southern Ocean: Results from inverse modeling and comparison with satellite-based estimates, Deep-Sea Res. II, 49, 1623-1644.

57. Telszewski, M., A. Chazottes, U. Schuster, A. J. Watson, C. Moulin, D. C. E. Bakker, M. González-Dávila, T. Johannessen, A. Körtzinger, H. Lüger, A. Olsen, A. Omar, X. A. Padin, A. Ríos, T. Steinhoff, M. SantanaCasiano, D. W. R. Wallace, and R. Wanninkhof (2009), Estimating the monthly $\mathrm{pCO}_{2}$ distribution in the North Atlantic using a self-organizing neural network, Biogeosciences, 6, 1405-1421. 
58. Borges, A. \& Co-Authors (2010). "A Global Sea Surface Carbon Observing System: Inorganic and Organic Carbon Dynamics In Coastal Oceans" in these proceedings (Vol. 2), doi:10.5270/OceanObs09.cwp.07.

59. Boutin, J., L. Merlivat, C. Hénocq, N. Martin, and J.B. Sallée (2008). Air-sea $\mathrm{CO}_{2}$ flux variability in frontal regions of the Southern Ocean from CARbon Interface OCean Atmosphere drifters. Limnol. Oceanogr. 53 (5), 2062-2079.

60. Körtzinger, A., U. Send, D.W.R. Wallace, J. Karstensen, and M. DeGrandpre (2008). The seasonal cycle of $\mathrm{O}_{2}$ and $p \mathrm{CO}_{2}$ in the central Labrador Sea: Atmospheric, biological and physical implications. Global Biogeochem. Cycles 22, GB1014, doi:10.1029/2007GB003029.

61. Feely, R. \& Co-Authors (2010). "An International Observational Network for Ocean Acidification" in these proceedings (Vol. 2), doi:10.5270/OceanObs09.cwp.29.

62. Garzoli, S. \& Co-Authors (2010). "Progressing Towards Global Sustained Deep Ocean Observations" in these proceedings (Vol. 2), doi:10.5270/OceanObs09.cwp.34.

63. Favali, P. \& Co-Authors (2010). "Seafloor Observatory Science" in these proceedings (Vol. 2), doi:10.5270/OceanObs09.cwp.28.

64. Martz, T. R., J. G. Connery, and K. S. Johnson (2010). Testing the Honeywell Durafet ${ }^{\circledR}$ for seawater $\mathrm{pH}$ applications, Limnology and Oceanography: Methods, 8 , 172-184.

65. Byrne, R. \& Co-Authors (2010). "Sensors and Systems for In Situ Observations of Marine Carbon Dioxide System Variables" in these proceedings (Vol. 2), doi:10.5270/OceanObs09.cwp.13.

66. Lefèvre, N., J.P. Ciabrini, G. Michard, B. Brient, M DuChaffaut, and L. Merlivat (1993). A new optical sensor for $p \mathrm{CO}_{2}$ measurements in seawater. Mar. Chem. 42, 189-198.

67. DeGrandpre, M.D., T.R. Hammar, S.P. Smith, and F.L. Sayles (1995). In situ measurements of seawater $p \mathrm{CO}_{2}$. Limnol. Oceanogr. 40, 969-975.

68. Körtzinger, A., Send, U., Lampitt, R. S., Hartman, S.,. Wallace, D. W. R. Karstensen, J., Villagarcia, M. G., Llinas, O. and DeGrandpre, M. D., 2008. Seasonal pCO2 cycle at $49^{\circ} \mathrm{N} / 16.5^{\circ} \mathrm{W}$ in the northeast Atlantic Ocean and what it tells us about biological productivity, J. Geophys.Res.,113, C04020, doi:10.1029/2007JC004347.

69. Hankin, S. \& Co-Authors (2010). "Data Management for the Ocean Sciences - Perspectives for the Next Decade" in these proceedings (Vol. 1), doi:10.5270/OceanObs09.pp.21

70. IPCC (2007). Climate Change 2007: The Physical Science Basis. Contribution of Working Group I to the Fourth Assessment Report of the Intergovernmental Panel on Climate Change [Solomon, S., D. Qin, M. Manning, Z. Chen, M. Marquis, K.B. Averyt, M.Tignor and H.L.
Miller (eds.)]. Cambridge University Press, Cambridge, United Kingdom and New York, NY, USA.

71. IMBER/SOLAS (2006). Joint SOLAS-IMBER Ocean Carbon Research: Implementation Plan, http://www.imber.info/products/Carbon_Plan_final.pdf.

72. Dore, J.E., R. Lukas, D.W. Sadler, M.J. Church, and D.M. Karl (2009). Physical and biogeochemical modulation of ocean acidification in the central North Pacific. Proc. Natl. Acad. Sci. USA 106, 12235-12240.

73. Kleypas, J.A., R.A. Feely, V.J. Fabry, C. Langdon, C.L. Sabine, and L.L. Robbins, 2006. Impacts of Ocean Acidification on Coral Reefs and Other Marine Calcifiers: A Guide for Future Research, report of a workshop held 18-20 April 2005, St. Petersburg, FL, sponsored by NSF, NOAA, and the U.S. Geological Survey, $88 \mathrm{pp}$.

74. Takahashi, T., T.T. Takahashi, and S.C. Sutherland (1995). An assessment of the role of the North Atlantic as a $\mathrm{CO}_{2}$ sink. Phil. Trans. R. Soc. Lond. B 348, 143152.

75. Takahashi, T., S.C. Sutherland, C. Sweeney, A. Poisson, N. Metzl, B. Tilbrook, N. Bates, R. Wanninkhof, R.A. Feely, C. Sabine, J. Olafsson, and Y. Nojiri (2002). Global sea-air $\mathrm{CO}_{2}$ flux based on climatological surface ocean $p \mathrm{CO}_{2}$, and seasonal biological and temperature effects. Deep-Sea Res. II 49, 1601-1622.

76. Tengberg, A., J. Hovdenes, J.H. Andersson, O. Brocandel, R. Diaz, D. Hebert, T. Arnerich, C. Huber, A. Körtzinger, A. Khripounoff, F. Rey, C. Rönning, J. Schimanski, S. Sommer and A. Stangelmayer (2006). Evaluation of a life time based optode to measure oxygen in aquatic systems. Limnol. Oceanogr.: Methods 4, 7-17. 